Article

\title{
Narratives and the Dialogue of Cultures of Knowledge: A Perspective on the Experience of the West and Africa
}

Uchenna Okeja

\section{Preliminary Observations and Introductory Remarks}

\begin{abstract}
A little story seems very apt as the beginning of our quest for the understanding of narratives and the dialogue of cultures of knowledge. This story is Chinua Achebe's adaptation of a Yoruba story. It goes this way: two farmers were working their farms on either side of a road. As they worked they made friendly conversation across the road. Then Eshu, god of fate and lover of confusion, decided to upset the state of peace between them. A god with a sharp and nimble imagination, he took his decision as quickly as lightning. He rubbed one side of his body with white chalk and the other side with charcoal and walked up the road with considerable flourish between the farmers. As soon as he passed beyond earshot the two men jumped from their work at the same time. And one said: "Did you notice that extraordinary white man who has just gone up the road?" In the same breath the other asked: "Did you see that incredible black man I have just seen?" In no time at all, the friendly questions turned into a violent argument and quarrel, and finally into a fight. As they fought they screamed: He was white! He was black! After they had belaboured themselves to their hearts' content they went back to their farms and resumed their work in gloomy and hostile silence. But no sooner had they settled down than Eshu returned and passed with even greater flourish between them down the road. Immediately the two men sprang up again. And one said: "I am sorry, my good friend. You were right; the fellow is white." And in the same breath the other farmer was saying: "I do apologize for my blindness. The man is indeed black, just as you said." And in no time again the two were quarrelling and then fighting. As they fought this time, they shouted: I was wrong! No, I was wrong!
\end{abstract}

1 See, Chinua Achebe, "Africa and Her Writers," in The Massachusetts Review, 14:3 (Summer 1973), 618-619.

(c) 2010 Uchenna Okeja

http://www.kritike.org/journal/issue 8/okeja december2010.pdf ISSN 1908-7330 


\section{Specifying the Meaning and Contexts of Dialogue}

The story above captures, to a certain extent, the scenario of human cognition and the very often claimed certainty thereof. There is always the tendency for the human mind to suppose that what it knows, it knows for sure. But the deception of appearance and the impossibility of knowing everything that can be known pushes the same human mind to doubt what it knows. The case is not very different in the oft invoked dialogue of cultures of knowledge. This kind of dialogue denotes that there is the need for complementary reflection. Like the two farmers in the above story, there is, however, the problem of getting the other parties to come to understand one's side of the story. The dialogue involved could very easily degenerate into acrimony, so much so that a productive argument is made impossible.

The story above shows the effects of 'absolutist exclusivism' which very often excoriates the other's views without even bordering to know enough about what it is all about. So, accounting for the dialogue implied means also accounting for the conditions that make it possible. This, I opine, means looking into the issue of the kind of interaction that would pass as dialogue of cultures of knowledge, for two people quarreling and shouting at each other, are engaged in some kind of interaction or exchange. They, however, cannot claim to be engaged in a dialogue. And this kind of interaction cannot be said to be what the dialogue of cultures of knowledge denotes. In this connection, therefore, it suffices to note that it is not all kinds of communicative interaction that pass for the interaction implied by dialogue. There are presuppositions that necessarily need to be ensured for any meaningful dialogue to take place. Aside the tenets of procedural discourse ethics which emphasize the importance of making sure that one does not commit a performatory self-contradiction in the argumentation process in the quest for rational consensus, dialogue of cultures of knowledge must take into account the foundational epistemologies that stand behind the entire quest. It must seek to articulate the ambit of the postulated otherness in order to determine if this presupposed epistemological framework is plausible.

The demand that dialogue of cultures of knowledge must evaluate its presupposed epistemological framework arises due to the fact that the invocation of dialogue itself presupposes a difference since people with the same point of view do not term whatever exchange of ideas they are engaged in as dialogue. They simply are engaged in a discussion. But to dialogue, divergent points of views are presupposed. And these points of view also have subjects representing them. That these subjects representing different points of view seek to dialogue points to the fact that they acknowledge that 1) there is a good inherent in the envisaged dialogue and 2) that they may not possess the fullness of cognition with regard to reality or the aspect of reality under consideration. These preliminary presuppositions of the subjects as they sashay into the dialogical forum could be regarded as the basic normative epistemological framework that spells out the contexts of viable dialogue. 
Without this, the dialogue will degenerate into unproductive soliloquy in the forms of either mutual admiration or misrepresentation.

Now the question is: how is dialogue possible? Or, differently put, what are the means by which the subjects represent their points of view in the dialogical process? This, to my mind, almost always takes the form of paradigmatic narratives. In engaging in dialogue of cultures of knowledge, the subjects involved in the dialogue try to make their points of view intelligible and to do this they need to narrate what informs their convictions and conclusions. This means that they, as the narrators, need to fulfill some epistemic-normative demands in order to be considered as credibly representing the point of view of the narratives they present and the narrative itself which is presented must satisfy certain conditions to be considered as authentic.

Without claiming to be able to spell out all that these two-tiered conditions are, it suffices to note that the entire quest is to prove the authenticity of both the narrator and the narrated. But with regard to the dialogue of cultures of knowledge, there is meta-narrative behind the entire endeavour which can be regarded as the factors of discursive historicity. The narrator and the narrated make recourse to this meta-narrative in order to establish their authenticity. When these factors of discursive historicity are in themselves impediments to dialogue, the entire dialogical process is jeopardized in such a manner that viability is precluded. This is why, akin to the observation above, dialogue of cultures of knowledge must evaluate from the outset the foundations of its epistemological presuppositions about otherness. This means confronting the factors of discursive historicity behind the scenes of the dialogue since they are the constituent elements at the foundations of the postulated otherness. The dialogue should not shy or explain away the factors of discursive historicity by appealing simply to reasons of moral impertinence or actuality. Rather, I opine that these factors of discursive historicity must be considered in themselves (and not just invoked as paradigms of intellectual moral failure of subjects of a particular knowledge tradition) by way of identifying and critically assessing them with a view to showing that they must be dispensed with for reasons of internal consistency and plausibility.

But what is meant by factors of discursive historicity at the foundation of the epistemological presupposition of otherness that, to a very large extent, make dialogue of cultures of knowledge traditions an imperative? Factors of discursive historicity refer directly to ossified conceptual frameworks and other elements of mental constructs of writing or narrating about subjects of a knowledge tradition but not for them. The concept refers to a tradition that creates a repetitive and reductive conceptualization of the subjects of a knowledge tradition by means of telling a single-story about them. To contextualize, factors of discursive historicity could be understood as narratives about Africa that have provided a beacon for a well-developed tradition of writing about Africa. Whereas the discursive nature of these factors consists in the fact that they maintain porous boundaries across disciplines; they move, in 
other words, from one area of intellectual discourse to another with utmost ease, their historicity denotes mainly their claim to authenticity based, not so much on plausible justifications but rather on the fact that all such writings fit into the tradition of writing about Africa. That is, that they conform to the status quo of a perennial intellectual discourse about Africa in the West. These factors of discursive historicity are related to narratives in the sense that they embody the things we look for in narratives as a corpus such as rich relations of consequence. Three areas where these factors have been in committed use are to be found in the subjects of anthropology, literature and philosophy. And in these three fields, the historicity implied comes out vividly.

\section{Representation of the Factors of Discursive Historicity}

To embark on the task of accounting for the representation of the factors of discursive historicity behind the scenes of dialogue of cultures of knowledge in a blanket-cover form will indeed be an impossible task. This accounts for the imperativeness of doing this from a context. The chosen context here is the African context. This is due to the fact that it is the context with which I am conversant by the accident of birth and reflective engagement.

\section{Anthropology}

Anthropological narratives about Africa display intensely this discursive historicity. Mudimbe accounts that the very name of the continent is itself a major problem. The Greeks named it Libya and used to call any black person an Aithiops. But then the confusion started with the Romans who had a province in their empire known as Africa. Added to this is the fact that their intellectuals used the same word (Africa) for the "tertia orbis terrarium pars" that is, the continent as we know it, being the third, after Europe and Asia. Besides, when the Europeans "discovered" the continent in the fifteenth century, the confusion became complete. ${ }^{2}$ There would have been little or no problem if the completeness of the confusion referred to was only about the proper way of naming the continent. In naming the continent, typifications of sorts with which the continent has become seamless ensued. And the overriding factor was, from the Greco-Roman epoch to the age of rediscovery and domestication in modern Europe, to underscore the otherness of the African. In historical and descriptive anthropology, the articulation of the otherness of Africa always takes into account a supposed discovery of the continent as its starting point. And this is the emergence of the tradition that says that "Africa was discovered in the fifteenth century. That, at least, is what most history books say. Professors teach it, students accept it as truth. In any

2 V.Y Mudimbe, The Idea of Africa (Indiana: Indiana University Press, 1994), preface to 
case, why doubt? The media propagate the veracity of the fact in the sagas of European explorers."3

Though this is accepted almost as a sacrosanct truth, it is often forgotten, nay seldom pointed out that:

... taken at its first meaning, this discovery (that is, this unveiling, this observation) meant and still means the primary violence signified by the word. The slave trade narrated itself accordingly, and the same movement of reduction progressively guaranteed the gradual invasion of the continent. Thus, doubtless, it was a discovery in this sense. Yet, one might very seriously wonder, is it really historically true that the continent was discovered in the fifteenth century? We do know what is inscribed in this discovery, the new cultural orders it allowed, and, in terms of knowledge, the texts that its discourses built and whose achievement is to be found in what I term the "colonial library." Looking again, however, it becomes apparent that indeed the fifteenth-century discovery was not the first contact of the continent with foreigners. Hence that discovery spells out only one viewpoint, the European. 4

It is exactly with this way of circumscribing Africa's coming to be that creates a locus for the articulation of the otherness of the continent. Earlier notions of the continent in European consciousness were not of this proclivity. And this is to be found in the Greek notions of the continent prior to the discovery in the fifteenth century.

In fact it has been noted that "contrary to many nations concerned with Africa only for her wealth in gold, ivory, and manpower, two millennia ago the Greeks looked at the Negroes as human beings, with admiration and in brotherly fashion."5 The information the Greek corpus offers about the African continent was, in actuality, relatively limited in comparison to that available for Asia, for example. Mudimbe, in this light, has suggested two approaches of understanding the Greek description of Africa: the mythic and the anthropological. What was the main concern here for Mudimbe was a critical appraisal of the revision of traditional history in intellectual discourses among black scholars. This, however, need not delay the discussion here since the main concern is with the change in conceptualization of Africa, whereby Africa became integrated in a reductive narrative that re-created it to become both a geography and condition which was not in keeping with the Earlier Greek approach mentioned above.

\footnotetext{
${ }^{3}$ Ibid., $16-17$.

${ }^{4}$ Ibid., 17.

${ }^{5}$ Alain Bourgeois, La Gréce antique la negritude, quoted in ibid., 20.
} 
This re-creation still had to do with naming and its attendant metaphors. How did this happen? What accounts, in essence, for the epistemological transmutation evident in the cognitive framework of 'the knowledge of the West about Africa?' To answer this question, it is important to start with noting that

... in most dictionaries of the sixteenth century, it is Latin nomenclature that reproduces itself. African is the equivalent of Afer, as substantive as well as adjective, and simply designates any person from the continent regardless of his or her colour. It translates Africanus .... For the Romans, Africa designates properly one of their provinces, and Africans, the Afri or Africani, its inhabitants .... Yet, in technical and literary works one finds another meaning, that of a third part of the world... which in this sense is the equivalent of the classical Greek Libya. $^{6}$

One tag for the continent Aethiops, introduced a textual confusion that conjures an image about the continent. Aethiops, which is the proper name of Vulcan's son in Greek mythology, is understood as the generic qualification of any dark-skinned person. On the other hand, however, Aethiopia, qualifies the continent: dicta a calore - colore - populorum quos solis vicinitas torret, that is, the land or the continent is called Aethiopia because of - and here it is a textual confusion that raises an image - the heat (calore) or the colour (colour) of the people living near the sun that burns them. ${ }^{7}$

It is with the onward movement of the characterization of Africa and its heydays in the period beginning with the fifteenth century that images of suggestive evaluations started being articulated in pari passu most discourses about Africa. To voice his recognition of the difficulty involved in proposing this way of understanding and situating the connection of Africa to the normative but negative images, Mudimbe noted that

... there are immense problems involved in designating the eighteenth century as the moment of strategic articulation of the concepts of primitiveness and savagery. Indeed, the great era of exploration took place between $1485 \ldots$ and $1541 \ldots$ Information and descriptions about the newly discovered "savages" found their way into the European consciousness, which strives to assert it Cogito toward what "it" defines as radically different. ${ }^{8}$

\footnotetext{
${ }^{6}$ Mudimbe, op. cit., 26.

${ }^{6}$ Ibid., 27.

8 Ibid., 28.
} 
With the foregoing, it should be evident that the transmutation of the articulation of Africa and the nexus this has with varied depictions of otherness was not an accident that intruded upon the intellectual spaceship from the blues. It had its own moments and enabling environment. Also, the time that the transmutation of the epistemological framework of the West's knowledge of Africa occurred is very informative. This is because the goal was, in its essential part, to legitimize the civilizing mission of the West in Africa.

Anthropological inquietude about the African formed the cradle upon which the "colonial library" was built. The fundaments were cast exactly at that point when there was a purposeful transmutation in the framework of the "knowledge of the West about Africa." Thus, the stereotypes constructed within this period became a founding "science" that determined the veracity of claims to authenticity about the works on the African person. Works in other fields of human knowledge had to conform to this already established "anthropological norm" of writing about Africa to be able to lay any claim to authenticity. This is why the explorers and navigators of preceding centuries, referred to in the above quotation from Mudimbe, met Africans and described them, sometimes without sympathy at all. They did so in the name of a difference and not necessarily because of an intellectual politics of prejudice. It is specifically this difference that is the "anthropological norm" that established a tradition of writing about Africa. As a corollary, in various disciplines, discourses about Africa started taking a definite shape; a shape in consonance with the narrative princints of the anthropological tradition. And, because disciplinary borders are porous, there ensued a progressive domestication of these narratives in the most unprecedented manner. Two areas where this domestication is very evident are literature and philosophy. Though the anthropological narrative is not very visible as being at work in the latter discipline (philosophy), it is nonetheless actively inherent in many of its discourses.

\section{Literature}

Chinua Achebe provides an insightful consideration of the subject matter in the area of literature. Achebe sought to demonstrate that Conrad's Heart of Darkness, better than any other work he knows displays that Western desire and need to understand Africa as the eccentric other. Conrad's Heart of Darkness, he notes "projects the image of Africa as 'the other world', the antithesis of Europe and therefore of civilization, a place where man's vaunted intelligence and refinement are finally mocked by triumphant bestiality."9 The novel opens with the River Thames but the actual story took place on the River Congo, the very antithesis of the Thames. The River Congo is quite decidedly not a River Emeritus. We are told that 'going up that river was like travelling back to the earliest beginning of the world.' These two rivers, Conrad wishes to

${ }^{9}$ Chinua Achebe, Hopes and Impediments (London: Heinemann, 1988), 2. 
inform, are very different, one good, the other bad. But, Achebe opines that "that is not the real point. It is not the differentness that worries Conrad but the lurking hint of kinship, of common ancestry. For the Thames too 'has been one of the dark places of the earth.' But if it were to visit its primordial relative, the Congo, it would run the risk of hearing grotesque echoes of its own forgotten darkness, and falling victim to an avenging recrudescence of the mindless frenzy of the first beginnings."10

The most interesting and revealing passages in Conrad's novel are about people. Achebe, quoting a passage from Conrad's novel remarks that the meaning of Heart of Darkness and the fascination it holds over the Western mind lies in the thought of the humanity of African. According to Achebe, "for Conrad things being in their place is of the utmost importance. 'Fine fellows cannibals - in their place,' he tells us pointedly. Tragedy begins when things leave their accustomed place." 11 The point here is that there is a place fitting for the fellows - Africans - Conrad is describing. They have to fit into the mould and cast of thinking about them which has been an established 'science' during the age of ethnographic, or rather, descriptive anthropology. Against the background of Conrad's depiction of a Western woman as opposed to an African woman, Achebe notes that

... the difference in the attitude of the novelist to these two women is conveyed in too many direct and subtle ways to need elaboration. But perhaps the most significant difference is the one implied in the author's bestowal of human expression to the one and the withholding of it from the other. It is clearly not part of Conrad's purpose to confer language on the 'rudimentary souls' of Africa. In place of speech they made 'a violent babble of unclothe sounds'. They 'exchanged short grunting phrases' even among themselves. ${ }^{12}$

In all, Conrad kept to this account of Africans, conferring speech on the savages only twice in his entire novel. The first occurs when cannibalism gets the better of them and the other was the famous announcement: 'Mistah Kurtz - he dead.' Against this background, Achebe was apt in noting that at first sight these instances might be mistaken for unexpected acts of generosity from Conrad. In reality, however, they constitute some of his best assaults. For, in the case of the cannibals the incomprehensible grunts that had thus far served them for speech suddenly proved inadequate for Conrad's purpose of letting the European glimpse the unspeakable craving in their hearts. And while weighing the necessity for consistency in the portrayal of the dumb brutes against the sensational advantages of securing their conviction by clear,
${ }^{10}$ Ibid., 3
11 Ibid.
${ }^{12}$ Ibid. 
unambiguous evidence issuing out of their own mouth Conrad chose the latter. ${ }^{13}$

A charge which might be brought forward against Achebe's reading of Conrad's novel was not only known to him but was also expressed by him. He was aware that "it might be contended, of course, that the attitude to the African in Heart of Darkness is not Conrad's but that of his fictional narrator, Marlow, and that far from endorsing it Conrad might indeed be holding it up to irony and criticism." 14 For Achebe, although Conrad made efforts to set up layers of insulation between himself and the moral universe of his story, it is yet pertinent to note that "if Conrad's intension is to draw a cordon sanitaire between himself and the moral and psychological malaise of his narrator his care seems ... totally wasted because he neglects to hint, clearly and adequately, at an alternative frame of reference by which we may judge the actions and opinions of his characters. It would not have been beyond Conrad's power to make that provision if he had thought it necessary."15

It might well be claimed that Conrad was just a child of his age; that it was not his fault that he flourished at a time when there was this tradition of looking at Africans with prejudice. But like Achebe noted:

Even after due allowances have been made for all the influences of contemporary prejudice on his sensibility there remains still in Conrad's attitude a residue of antipathy to black people which his peculiar psychology alone can explain.... Conrad certainly had a problem with niggers.... Sometimes his fixation on blackness is equally interesting as when he gives us this brief description: 'A black figure stood up, strode on long black legs, waving long black arms' - as though we might expect a black figure striding along on black legs to wave white arms! But so unrelenting is Conrad's obsession. ${ }^{16}$

One striking insight in Achebe's appraisal of Conrad's novel which connects the concern here with discursive historicity to the domestication of stereotypes about Africans in literature is this:

Conrad did not originate the image of Africa which we find in his book. It was and is the dominant image of Africa in the Western imagination and Conrad merely brought the peculiar gifts of his own mind to bear on it...the west seems to suffer deep anxieties about the precariousness of its civilization and to have a need for constant reassurance by comparison with Africa. If

\footnotetext{
${ }^{13}$ Ibid.

${ }^{14}$ Ibid., 7.

15 Ibid.

${ }^{16}$ Ibid., 9 .
} 
Europe, advancing in civilization, could cast a backward glance periodically at Africa trapped in primordial barbarity it could say with faith and feeling: There go I but for the grace of God. Africa is to Europe as the picture is to Dorian Gray - a carrier on to whom the master unloads his physical and moral deformities so that he may go forward, erect and immaculate. Consequently Africa is something to be avoided just as the picture has to be hidden away to safeguard the man's jeopardous integrity. Keep away from Africa, or else! ${ }^{17}$

This tradition of writing about Africa has its grips today, not just on the imagination of the so-called West but also beyond. There are many other books of literature that have domesticated this tradition. The effect is the perpetuation of the narratives of discursive historicity that have become paradigmatic about Africa since the epistemological turn in the framework of 'writing about Africa.' A very good study of literatures in this regard was provided by Dorothy Hammond and Alta Jablow in their book on the subject matter. ${ }^{18}$ But for our purposes here, the foregoing consideration seems to be adequate. This is because the main aim is not so much with an exhaustive account of literature from this perspective but rather with showing that the stereotypes of discursive historicity did in fact have their day in literatures connected with the very notion or idea of the African continent or the African as a part of the human race.

\section{Philosophy}

An influential trinity that stand at the helm of Western philosophy's domestication of narratives of discursive historicity in relation to the African is to be found in the philosophical figures of Hume, Hegel and Kant. For want of space, only the exemplification of this in Kant will be sought below, however briefly. The late vibrant postcolonial philosopher, Emmanuel Chukwudi Eze in his study of Kant from the perspective of the colour of reason noted that Kant classified human beings based on the colour of their skin. ${ }^{19}$ This was because Kant took skin colour as evidence of a racial difference in terms of inferiority or otherwise. Following this train of thought, Kant provided a chart which accounts for the hierarchical order of hues of the skin colour of human beings beginning with the superior down to the inferior. The chart runs thus:

STEM GENUS: white brunette

First race, very blond (northern Europe), of damp cold

${ }^{17}$ Ibid., 12.

18 Dorothy Hammond and Alta Jablow, The Africa That Never Was: Four Centuries of British Writing About Africa (London: Waveland Press, 1992).

19 Emmanuel Chukwudi Eze, Post-colonial African Pbilosopby (Cambridge: Blackwell Publishers, 1997), 115. 


\author{
Second race, Copper-Red (America), of dry cold \\ Third race, Black (Senegambia), of dry heat \\ Fourth race, Olive-Yellow (Indians), of dry heat ${ }^{20}$
}

But why is the chart arranged thus; what does Kant aim at with such a classification? The assumption behind this arrangement is precisely Kant's belief that the ideal skin colour is the white (the white brunette) and the other skin colours are merely degenerative developments from the original white. To buttress this point, Kant noted that "humanity exists in its greatest perfection in the white race. The yellow Indians have a smaller amount of talent. The Negroes are lower, and the lowest are a part of the American peoples." ${ }^{21}$ Full humanity exists only in those with white skin colour for Kant and the blackness of one's skin could be an indication of stupidity. This is evident in Kant's claim when, in his evaluation of a statement made by an African, he dismissed the fellow by saying that "this fellow was quite black from head to foot, a clear proof that what he said was stupid."22

This, then, is the main point that stands at the basis of the discursive historicity about African's otherness; the assertion of their inhumanity by either withholding or not fully attributing humanness to them. To cap it up, Kant makes evident the discursiveness of his opinions of the African by exhibiting something which is characteristic of this sort of inquiry, namely, the recourse to the tradition of writing about Africa whereby appeal to the established pattern (by quoting supposedly authoritative sources) is what confers authenticity and not the claims of the discourse itself. Thus, in keeping with this sort of narrative tradition, Kant quotes Hume to make his characterization of the African authentic. He writes:

Mr Hume challenges anyone to cite a simple example in which a Negro has shown talents, and asserts that among the hundreds of thousands of blacks who are transported elsewhere from their countries, although many of them have been set free, still not a single one was ever found who presented anything great in art or science or any other praiseworthy quality; even among the whites some continually rise aloft from the lowest rabble, and through superior gifts earn respect in the world. So fundamental is the difference between the two races of man, and it appears to be as great in regard to mental capacities as in colour. ${ }^{23}$

${ }^{20}$ Immanuel Kant, On the Different Races of Man, in Earl W. Count, ed., This is Race: An Anthology Selected from the International Literature on the Races of Man (New York: Schuman, 1950), 23.

${ }^{21}$ Immanuel Kant, Physische Geographie, quoted in Eze, op. cit., 118.

22 Immanuel Kant, Observations on the Feeling of the Beautiful and Sublime, trans. by John T. Goldthwait (Berkeley: University of California Press, 1960) 113.

${ }^{23}$ Ibid., 110-111. 


\section{Implications and the Way Forward}

What do these factors of discursive historicity mean for the dialogue of knowledge traditions especially with regard to the dialogue between Africa and the west? Among many things, they mean the following: 1) that genuine dialogue between the two traditions is impossible with these factors operating behind the scenes of the dialogue, especially as evident in the presupposition of the epistemological framework at the basis of the current endeavour of the dialogue which postulates otherness as its point of departure and 2) that what is most important in the dialogue of knowledge traditions is that, apart from the insistence that the different traditions should be considered as equals, ${ }^{24}$ the implicit epistemic injustice should be critiqued in such a way that they will cease to reconstitute themselves in different forms. It is only when this is achieved that there will be viable and genuine dialogue. This is because, insisting only on the equality of knowledge traditions as a fundamental postulate of the dialogue will conjure the picture that these traditions were not equal somehow, sometime ago. But if equality was absent, what then will bring it about?

The point about epistemic injustice needs to be enunciated a little further in order to show how it impinges on the quest for dialogue of knowledge traditions. First off, it is pertinent to note that epistemic injustice does not refer to distributive fairness with regard to epistemic goods such as information or education. The meaning of the term consists most fundamentally in a wrong done to someone specifically in their capacity as a knower. This could take the forms of testimonial and hermeneutical injustice.

Testimonial injustice occurs when prejudice causes a hearer to give a deflated level of credibility to a speaker's word; hermeneutical injustice occurs at a prior stage, when a gap in collective interpretive resources puts someone at an unfair disadvantage when it comes to making sense of their social experiences.... We might say that testimonial injustice is caused by prejudice in the economy of credibility; and that hermeneutical injustice is caused by structural prejudice in the economy of collective hermeneutical resources. ${ }^{25}$

Thus, epistemic injustice arises in the context of dialogue of cultures of knowledge when the factors of discursive historicity discussed above leads to an imbalance of narratives. This imbalance could lead to credibility overload,

24 Of course equality of the dialogue partners is imperative. With regard to NorthSouth efforts at dialogue, the big brother attitude of the North needs to be discarded if any genuine dialogue is to take place. For more on this see, Chinua Achebe, Hopes and Impediments, 14-19.

${ }_{25}$ Miranda Fricker, Epistemic Injustice, Ethics and Power of Knowing (Oxford: Oxford University Press, 2007), 2. 
credibility deficit or, in some cases, to total epistemic disenfranchisement. In all, however, the way forward will consist in creating a balance of narratives where the epistemological framework of dialogue is based, not on the postulation of otherness, perpetuated by the phenomenon of experts on Africa, but on a just epistemic framework that moves the epistemic center from a one dimensional narrative to a well-rounded narrative. This way, the subjects of the dialogue will ultimately abandon unwholesome thoughts while recognizing the need for epistemic justice and enfranchisement.

Department of Philosophy, Goethe Universität-Frankfurt am Main, Germany

\section{References}

Achebe, C., Hopes and Impediments (London: Heinemann, 1988).

"Africa and Her Writers," in The Massacbusetts Review, 14:3 (Summer 1973).

Eze E.C., Post-colonial African Philosophy (Cambridge: Blackwell Publishers, 1997).

Fricker M., Epistemic Injustice, Ethics and Power of Knowing (Oxford: Oxford University Press, 2007).

Hammond D. and Jablow A., The Africa That Never Was: Four Centuries of British Writing About Africa (London: Waveland Press, 1992).

Kant I., Anthropology From a Pragmatic Point of View, trans. by Mary J. Gregor (The Hague: Nijhoff, 1974).

, Observations on the Feeling of the Beautiful and the Sublime, trans. by John T. Goldthwait (Berkeley: University of California Press, 1960).

"On the Different Races of Man," in Count W. E., This is Race: An Anthology Selected from the International Literature on the Races of Man (New York: Schuman, 1950).

Physische Geographie, in Kant I., Gesammelte Schriften, (Berlin, Reimer 1900-1966).

Mudimbe V.Y., The Idea of Africa (Indiana: Indiana University Press, 1994). 